\title{
Study on preparation of metal-organic framework membrane and pore size adjustment method
}

\author{
Yang Hui ${ }^{1, *}$, Zhang Jiaqi ${ }^{1}$, He Huan ${ }^{1}$ \\ ${ }^{1}$ Shenyang jianzhu university municipal and environmental engineering college, Shenyang, Liaoning 110168;
}

\begin{abstract}
Metal-organic framework materials have the advantages of large specific surface area, high porosity, strong adjustability of framework structure, adjustable chemical and thermal properties, etc., and can be used as ideal membrane materials. In this paper, the preparation methods and conditions of several common metal-organic framework materials, as well as how to adjust the pore size, are reviewed, and the advanced membrane treatment technology is prospected.
\end{abstract}

\section{Foreword}

Metal-organic framework material is another important new type of porous material besides zeolite and carbon nanotubes. As a new type of porous material with the most heat and foresight, it has incomparable advantages compared with traditional inorganic materials such as silicate molecular sieve, phosphate molecular sieve and porous materials such as carbon and silicon. Although the pore structure of traditional inorganic porous materials is regularly arranged, the pore size can not be controlled systematically. The pore size of metal-organic framework membrane can be easily adjusted by changing metal source, organic ligand, reaction solvent and temperature. In this paper, several commonly used preparation methods of organic metal skeleton membranes and pore size adjustment methods are introduced.

\section{Preparation method of metal-organic framework film}

Common preparation methods of metal-organic framework films include in-situ synthesis, secondary growth, mixed matrix membrane, chemical modification of carrier surface and layer-by-layer growth.

\subsection{In-situ synthesis method}

In-situ synthesis is a method of soaking the carrier without any crystal in the precursor solution, thus growing a large number of crystals. At first, the metal-organic framework material forms crystal nucleus, and then, it grows alternately to produce continuous thin films. Huang Aisheng's research group ${ }^{[1]}$ used different coupling agents (such as silane, dopamine, etc.) as connecting carriers, and prepared different ZIF series metal-organic framework films by in-situ synthesis. Wang prepared PA/ZIF-8 nanocomposite films by in situ growth and interfacial polymerization. first, the ZIF- 8 particles were grown in situ on the supported polysulfone porous film as a interlayer, and then the polyamide was encapsulated on the ZIF-8 interlayer by interfacial polymerization, and finally the film with interlayer was formed. the content of the ZIF- 8 and the number of layers of themembrane can also be controlled by repeatedly growing in the precursor solution.

\subsection{Secondary growth method}

Secondary growth method, also called crystal coating method, refers to coating the seed crystal first in the process of preparing the film, then placing the seed crystal in the solution phase, and growing again to form the film. Although the operation of the secondary growth method is more complicated than that of the in-situ growth method, the control advantages of the secondary growth method in pore structure, crystal orientation and film thickness are obvious. See table 1 for the specific method and operation process. Zhao Zhenxia et al ${ }^{[2]}$ successfully prepared MOF- 5 crystal films on $\mathrm{Al}_{2} \mathrm{O}_{3}$ glass slides by secondary growth method.

Table 1,Specific method and operation process of secondary growth method

\begin{tabular}{c|c}
\hline Way & Operation and conclusion \\
\hline Manual crystal \\
coating method & $\begin{array}{c}\text { Firstly, the surface of } \alpha-\mathrm{Al}_{2} \mathrm{O}_{3} \text { carrier was } \\
\text { modified by polyethyleneimine, and then } \\
\text { the MOF synthesized by } \mathrm{Cu}\left(\mathrm{NO}_{3}\right) 2 \cdot 3 \mathrm{H}_{2} \mathrm{O} \\
\text { and } 4,4-\text { hexafluoroisopropylidene benzoic } \\
\text { acid was connected with the modified } \\
\alpha-\mathrm{Al}_{2} \mathrm{O}_{3} \text { to prepare a continuous and dense } \\
\text { MOF film }\end{array}$ \\
\hline
\end{tabular}

*Corresponding author: yanghui-73@163.com 


\begin{tabular}{|c|c|}
\hline $\begin{array}{l}\text { Spin coating } \\
\text { method }\end{array}$ & $\begin{array}{l}\text { 1-D Cu (ii)-BTC seeds with suitable } \\
\text { concentration were spin-coated on } \alpha-\mathrm{Al}_{2} \mathrm{O}_{3} \text {, } \\
\text { and then the dense } \mathrm{Cu}_{3}(\mathrm{BTC})_{2} \text { films were } \\
\text { successfully prepared by secondary growth }\end{array}$ \\
\hline $\begin{array}{l}\text { Immersion-pullin } \\
\mathrm{g} \text { method }\end{array}$ & $\begin{array}{l}\text { The modified hollow ceramic fiber carrier } \\
\text { was immersed in } \mathrm{Cu}_{3}(\mathrm{BTC})_{2} \text { seed solution } \\
\text { and then pulled out. The } \mathrm{Cu}_{3}(\mathrm{BTC})_{2} \\
\text { membrane with good gas separation } \\
\text { performance and continuous compactness } \\
\text { was prepared by secondary growth in } \\
\text { hydrothermal reaction kettle }\end{array}$ \\
\hline $\begin{array}{l}\text { Reaction seed } \\
\text { method }\end{array}$ & $\begin{array}{c}\text { The } \alpha-\mathrm{A} 12 \mathrm{O} 3 \text { sheet and the solution } \\
\text { containing only } 1,4 \text {-terephthalic acid ligand } \\
\text { were subjected to hydrothermal reaction, } \\
\text { and Al reacted with the ligand to form } \\
\text { MIL-53 seed layer, which was secondarily } \\
\text { grown with } \mathrm{H}_{2} \mathrm{BDC} \text { to obtain dense MIL-53 } \\
\text { film }\end{array}$ \\
\hline $\begin{array}{c}\text { Thermal seed } \\
\text { method }\end{array}$ & $\begin{array}{l}\text { The } \alpha-\mathrm{A} 12 \mathrm{O} 3 \text { sheet was heated at high } \\
\text { temperature, and the synthesized HKUST-1 } \\
\text { seed solution was dropped onto the carrier. } \\
\text { This method mainly uses the strong bond } \\
\text { between seed crystal, copper ion and ligand } \\
\text { homobenzoic acid and carrier } \alpha-\mathrm{Al}_{2} \mathrm{O}_{3} \text { at } \\
\text { high temperature to continue secondary } \\
\text { growth and prepare HKUST- } 1 \text { film }\end{array}$ \\
\hline
\end{tabular}

\subsection{Mixed matrix membrane method}

Mixed matrix membrane (MMM) is a kind of composite material composed of polymer matrix, in which a large number of particles are embedded. MMM not only inherits the properties of polymer, but also is influenced by filling materials. It has the mechanical elasticity and high porosity of polymer materials. In the mixed matrix membrane method, firstly, alumina particles with porous structure formed by the traditional porous alumina preparation method are dispersed and mixed in a polymer solution, and then a mixture which is easy to coat and diffuse is formed; then, the film is scraped by a scraper or prepared by a spin coating method; and finally, the solvent is volatilized by curing or drying, so that the metal-organic framework film with unsupported characteristics is obtained ${ }^{[3]}$. Materials such as IR-MOF1,HKUST-1,UiO-66 and ZIFs have been used in the preparation of continuous polycrystalline membranes, both of which have relatively mature preparation routes, but MIL-101,UiO-67 and NU-1000 have not been used to prepare polycrystalline membranes. Therefore, the preparation of these porous membranes can be completed by mixed matrix membrane method.

Although the mixed matrix membrane has good application potential, it also has its own limitations. First, because of the existence of no pore substrate, the permeability of the mixed matrix membrane is worse than that of the pure organometallic skeleton membrane. to solve this problem, we need to further control the MOF content in the mixed MOF, because higher MOF content will allow MOF to perform better operations. At the same time, the MOF particles of organometallic skeleton are easy to unite and the dispersion is poor in the mixed matrix membrane, which is also the main factor affecting the void defects in the membrane.

\section{4 .Chemical modification of carrier surface}

Continuous membrane with high concentration and no defects can improve the flux of membrane, and then enhance the selective permeability of membrane. In the preparation process of mixed matrix membrane, when pure metal-organic framework materials are combined with polymer materials, membrane defects or cracks easily occur, which directly affect the chemical properties of the membrane,This problem can be improved by modifying the surface of metal-organic framework, The chemical modification of carrier surface is a common method to modify metal-organic framework materials. The polymer in the mixed matrix film was modified by silanization modification, which realized the versatility of the film, and the interaction between materials was also improved, so that covalent bonds were formed between the polymer and the film, and then a strong interaction was generated.

Carrier surface chemical modification methods are often used to enhance interfacial interactions between metal organic framework materials/polymer. Basu et al.$^{[4]}$ studied a variety of organometallic frameworks, such as HKUST-1、ZIF-8、MIL-47 and MIL-53(al). compared with pure membranes, the flux of these metal-organic framework materials added to the membranes formed in the polydimethylsiloxane polymer matrix increased, but the selective permeation weakened. sem images show that there are voids around the porous ceramic particles, indicating that the adhesion between the porous ceramic particles and the polymer is weak, so the membrane has no selective permeation channels. Because the polymer is nonpolar and has weak surface interaction with the polymer, the adhesion between the polymer and the polymer is very weak.

\subsection{Layer by layer growth method}

Layer-by-layer growth method refers to coating the film substrate with metal salt solution and organic ligand in turn. Excess precursor can be removed by rinsing the substrate with pure solvent. The film thickness can be accurately controlled by using discontinuous crystallization process of organic metal skeleton. This method needs to be carried out under mild conditions, and is suitable for large-scale production of organometallic skeleton films. Shekhah et al,used this method to prepare ZIF-8 film on $\mathrm{Al}_{2} \mathrm{O}_{3}$ substrate. Zinc nitrate solution and methyl imidazole solution are continuously deposited on the substrate, which can control the thickness of the film at 0. 5-1.6 $\mu \mathrm{m}$. However, in $\mathrm{C}_{3} \mathrm{H}_{6} / \mathrm{C}_{3} \mathrm{H}_{8}$ gas separation, the thicker the 
film has poor selectivity and gas permeability, which may be due to the relatively poor internal microstructure of the prepared ZIF- 8 crystal layer. Because the synthesis conditions of this method are mild, it is suitable for assembling organometallic skeleton membrane on polymer substrate. While many organometallic framework films can be prepared by this method, these SURMOF films are more suitable for scientific research, because the growth and preparation process of MOF films prepared by this method is very time-consuming and complex. More problems will be encountered in mass production .

To sum up, the preparation methods, advantages and disadvantages of common metal-organic framework films are shown in Table 2 .

Table 2, Preparation methods, advantages and disadvantages of common organometallic skeleton membranes

\begin{tabular}{|c|c|c|}
\hline $\begin{array}{l}\text { Preparation } \\
\text { method }\end{array}$ & Advantage & Disadvantage \\
\hline $\begin{array}{l}\text { In situ growth } \\
\text { method }\end{array}$ & $\begin{array}{l}\text { Crystal or films } \\
\text { with nanometer } \\
\text { scale can be } \\
\text { prepare }\end{array}$ & $\begin{array}{l}\text { The membrane that } \\
\text { can be prepared is } \\
\text { relatively simple }\end{array}$ \\
\hline $\begin{array}{l}\text { Secondary growth } \\
\text { method }\end{array}$ & $\begin{array}{l}\text { Controllable seed } \\
\text { crystal grows } \\
\text { evenly, and the } \\
\text { produced film is } \\
\text { continuous, with } \\
\text { few defects and } \\
\text { compactness }\end{array}$ & $\begin{array}{l}\text { Operation is more } \\
\text { complicated than } \\
\text { in-situ growth }\end{array}$ \\
\hline $\begin{array}{c}\text { Mixed matrix } \\
\text { membrane method }\end{array}$ & $\begin{array}{c}\text { Various types of } \\
\text { organometallic } \\
\text { skeleton films can } \\
\text { be prepared }\end{array}$ & $\begin{array}{l}\text { Compared with pure } \\
\text { organometallic } \\
\text { skeleton films, the } \\
\text { permeability is poor }\end{array}$ \\
\hline $\begin{array}{l}\text { Chemical } \\
\text { modification of } \\
\text { carrier surface }\end{array}$ & \begin{tabular}{|} 
The MOF \\
membrane \\
synthesized by \\
post-modification \\
method forms a \\
covalent composite \\
structure, which is \\
far better than the \\
traditional mixed \\
matrix membrane, \\
and its selectivity is \\
also improved
\end{tabular} & $\begin{array}{l}\text { The film forming } \\
\text { conditions are } \\
\text { difficult to achieve } \\
\text { and the operation is } \\
\text { complicated }\end{array}$ \\
\hline
\end{tabular}

\begin{tabular}{|c|c|c|}
\hline $\begin{array}{l}\text { Layer by layer } \\
\text { growth method }\end{array}$ & $\begin{array}{c}\text { The thickness of } \\
\text { the film can be } \\
\text { accurately } \\
\text { controlled by using } \\
\text { discontinuous } \\
\text { crystallization } \\
\text { process of organic } \\
\text { metal skeleton, and } \\
\text { many kinds of films } \\
\text { can be produced }\end{array}$ & $\begin{array}{l}\text { The growth } \\
\text { preparation process } \\
\text { is very } \\
\text { time-consuming and } \\
\text { the synthesis } \\
\text { process is complex, } \\
\text { which is only } \\
\text { practical and } \\
\text { scientific research } \\
\text { and is not suitable } \\
\text { for mass production }\end{array}$ \\
\hline
\end{tabular}

\section{Method for adjusting pore size of metal organic framework materials}

The pore size of organometallic framework material can be adjusted by changing the organic ligand and length, or changing the metal source, reaction solvent and temperature.

\subsection{The regulation of organic ligands and len gth on the pore size of metal-organic framew ork materials}

One of the important components of metal-organic framework includes organic ligands, so by adjusting the length of organic ligands, the pore sizeof metal-organic framework can be controlled. Yaghi research group and others $^{[5]}$ used phthalic acid (1,4-BDC), 2,6- naphthalene malonic acid (2,6-NDC), 4,4'- biphenyl malonic acid (4,4-BPDC) and 4,4'- terphenyl malonic acid (4,4-TPDC) as organic ligands. By changing the length of the ligand, thepore size can be adjusted from $0.38 \mathrm{~nm}$ to $2.88 \mathrm{~nm}$,Wang Keke et al,[6] designed and synthesized three kinds of porous materials with different pore sizes (Hf-FUM, Hf-BDC and Hf-BPDC).

\subsection{Metal sources control the pore size of $\mathrm{m}$ etal-organic framework materials}

In the process of adjusting the metal-organic framework, the selection of metal source can have a certain influence on the adjustment of material pore size. A majority of metal sources are subpopulations of transition metal ions, such as $\mathrm{Fe}^{3+}, \mathrm{Zn}^{2+}, \mathrm{Cu}^{2+}$, because the subterranean orbitals of these metal ions are not filled with electrons and can be coordinated by lone pairs of electrons of organic ligands. Rose et al ${ }^{[7]}$ prepared $\mathrm{Cu}$-FDA,Fe-FDA and Al-FDA with 2,5- furandicarboxylic acid (FDA) as organic ligand and $\mathrm{Cu}^{2+}, \mathrm{Fe}^{3+}$ and $\mathrm{Al}^{3+}$ as metal sources under the same experimental conditions. The aperture of $\mathrm{Cu}$-FDA is smaller than that of Al-FDA, and its average aperture is $0.66 \mathrm{~nm}$. In Fe-FDA materials, the pore size distribution ranges from $0.6 \mathrm{~nm}$ to $10 \mathrm{~nm}$. Therefore, under the same organic ligands and experimental conditions, coordination with different metal ions such as $\mathrm{Fe}^{3+}, \mathrm{Zn}^{2+}, \mathrm{Cu}^{2+}$ and $\mathrm{Al}^{3+}$ as metal sources can be effectively controlled. 


\subsection{Regulation of the pore size of metal-orga nic framework materials by reaction solvent a nd reaction temperature}

Different solvents have great differences in polarity,During the formation of metal-organic framework materials, weak interaction may occur between solvent molecules and framework, which can stabilize metal-organic framework materials and control the pore size of framework materials. Sahiner et al ${ }^{[8]}$ prepared metal-organic framework materials with trimellitic acid $\left(\mathrm{C}_{9} \mathrm{H}_{6} \mathrm{O}_{6}\right)$ as organic ligand, $\mathrm{CuSO} 4$ as metal source and ethanol and deionized water as solvents. When ethanol is used as the reaction solvent, the synthesized material does not produce mesoporous structure. When deionized water was used as the reaction solvent, the results were different from those of ethanol, and mesoporous structure appeared in the synthesized materials, with a pore size of $15.56 \mathrm{~nm}$. Gérard Férey's research group ${ }^{[9]}$ found that due to the different dielectric constants of water at different temperatures and the different coordination capacities and modes of carboxylic acid ligands, the structures and pore sizes of the generated organometallic skeleton materials are different.

\section{Conclusion and prospect}

The preparation method of hybrid membrane based on metal-organic framework material has important academic value and industrial application prospect. With regard to the preparation of organometallic skeleton films, many research groups have explored the preparation methods of different series of organometallic skeleton films with excellent film properties through experiments, but the preparation technology still has some shortcomings, the control of intergranular defects is still the main problem, and the high raw material cost is also worthy of attention.

Similarly, suitable pore size plays a key role in the application of metal-organic framework materials. Compared with traditional inorganic or organic porous materials, metal-organic framework materials can easily control organic ligands, metal sources, solvents and reaction temperatures to construct suitable pore sizes.

\section{Acknowledgments}

Thanks to the support of the "13th five-year plan"water research group for this study, the integrationand application of water pollution control and water environment management technology in liaohe river basin, the subject of this study (2018ZX07601001), provided the data of this study.I wouldlike to thank the teachers of the school of environment of shenyang jianzhu university for their hardwork and the students who helped me with this paper.

\section{References}

1. Huang A, Chen Y, Wang N, et al. A highly permeable and selective zeolitic imidazolate framework ZIF-95 membrane for $\mathrm{H}_{2} / \mathrm{CO}_{2}$ separation J].Chemical Communications.2012,48(89):10981-10983.

2. Zhao Zhenxia,Preparation of MOF-5 membrane with metal-organic framework and its $\mathrm{CO} 2$ gas permeation and separation performance,Ph.D,Thesis, East China University of Science and Technology. 2009.

3. Denny, M. S; Cohen, S M. In Situ Modification of Metal-Organic Frameworks in Mixed-matrix Membranes Angew. Chem. Int. Ed. 2015, 54, 9029-9032.

4. Basu, S; Maes, M. Odena, A. C. Alaerts, L; De Vos, D. E; Vankelecom, L. F. J.Solvent Resistant Nanofiltration (SRNF) Membranes Based on Metal-Organic Frameworks. J Membr. Sci. 2009, 344, 190-198

5. Eddaoudi M, Kim J, Rosi N, et al. Systematic design of pore size and funtionality in isoretieular MOFs and their APPli2 cation in methane storage[J]. Science, 2002, 295(18): 469-472

6. Wang Keke, Li Liangsha, Huang Hongliang, et al. Pore size control and adsorption properties of hafnium metal-organic framework materials [J]. Chinese journal of chemical engineering, 2014, may: 1696-1705 .

7. Rose M, Weber D, Lotsch B V, et al. Biogenic metalorganic frameworks: 2,5-furandicarboxylic acid as versatile building block[J]. Micropor \& Mesopor Mater, 2013, 181: 217-221 .

8. Sahiner N, Sel K, Ozturk O F, et al. Facile synthesis and characterization of trimesic acid- $\mathrm{Cu}$ based metal organic frameworks[J]. Appl Surf Sci, 2014, 314: 663-669 .

9. Livage C, Egger C, Férey G. hydrothermal versus nonhydrothermal synthesis for the preparation of organicinorganic solids: the example of cobalt(II) succinate[J]. Chem Mater, 2001, 13(2): 410- 414 